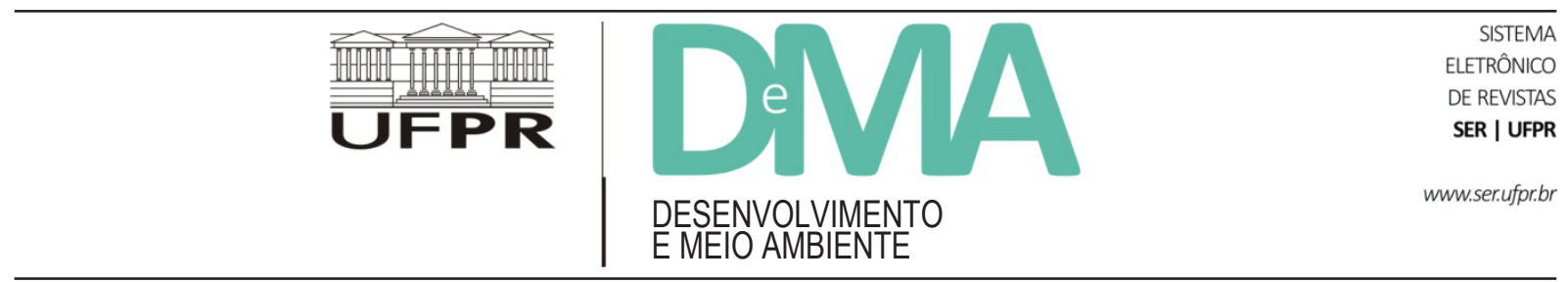

\title{
Extrativismo e desenvolvimento no contexto da Amazônia brasileira
}

\section{Extraction and Development in the Context of the Brazilian Amazon}

\author{
Danielle Wagner SILVA ${ }^{1 *}$, Livio Sérgio CLAUDINO², Carlos Douglas OLIVEIRA ${ }^{3}$, Ana Paula MATEI ${ }^{4}$, Rumi \\ Regina $\mathrm{KUBO}^{4}$ \\ ${ }^{1}$ Universidade Federal do Oeste do Pará (UFOPA), Santarém, PA, Brasil. \\ ${ }^{2}$ Universidade Federal do Pará (UFPA), Abaetetuba, PA, Brasil. \\ ${ }^{3}$ Rede Brasileira de Pesquisa e Gestão em Desenvolvimento Territorial (RETE), Brasília, DF, Brasil. \\ ${ }^{4}$ Universidade Federal do Rio Grande do Sul (UFRGS), Porto Alegre, RS, Brasil. \\ *E-mail de contato: danicawagner@yahoo.com.br
}

Artigo recebido em 16 de dezembro de 2015, versão final aceita em 3 de agosto de 2016.

RESUMO: Tendo como pano de fundo o debate sobre a relação entre uso dos recursos naturais, economia e sustentabilidade, neste trabalho objetiva-se discutir o lugar do extrativismo no contexto do Desenvolvimento considerando as diferentes perspectivas sobre essa atividade na Amazônia brasileira. Com base em revisão de literatura e dados secundários, contextualiza-se que historicamente as estratégias de desenvolvimento pensadas para a região amazônica brasileira são pautadas em atividades extrativistas promovidas pelos detentores de poder político e econômico e fomentadas pelo Estado. Atualmente, é recorrente no discurso de acadêmicos e de porta-vozes do governo, de movimentos sociais e de empresas, a necessidade do repensar o uso dos recursos naturais, agregando valor aos produtos extrativistas e valorizando o conhecimento das populações tradicionais. Discute-se o reconhecimento da diversidade de populações, de ecossistemas e de formas de gestão dos recursos naturais, emergindo novos atores, novos produtos e conflitos. Todavia, nesse cenário de disputas, segue o desafio da operacionalização de tais princípios em termos de estratégias para o desenvolvimento.

Palavras-chave: atividades extrativistas; recursos naturais; desenvolvimento sustentável.

ABSTRACT: Having as background the debate about the relationship between the use of natural resources, economy and sustainability, the objective of this paper is to discuss the place for extraction in the context of development considering the different perspectives of this activity in the Brazilian Amazon. Based on literature review and secondary data it is contextualized that historically the development strategies designed to Brazil's Amazon region are guided in extractive activities promoted by the holders of political and economical power and promoted by the state. Currently, it recurs in academic discourses and government spokesmen, social movements and companies, the need to rethink the use of natural resources, adding value to extractive products and enhancing 
the knowledge of traditional populations. It discusses the recognition of the diversity of populations, ecosystems and ways of managing natural resources, emerging new actors, new products and conflicts. However, in this dispute scenario, the challenge of implementing these principles in terms of strategies for development continues.

Keywords: extractive activities; natural resources; sustainable development.

\section{Introdução}

Nas duas últimas décadas, o uso e a gestão dos recursos naturais têm sido temas recorrentes nos debates acadêmicos e políticos sobre desenvolvimento. De modo geral, para alguns atores (tanto acadêmicos como políticos), florestas, rios, solos, fauna e flora representam oportunidades de realização de atividades econômicas com vistas, sobretudo, ao crescimento econômico. Para outros, estão associados à constituição de um modo de vida peculiar, distinto daquele que se evidencia no mundo moderno. Essas diferentes situações, e suas matizes, são aplicadas ao caso da Amazônia Brasileira, região cujos processos sociais que desencadearam sua ocupação são embasados na exploração dos recursos naturais como atividades econômicas, tais como apontam os estudos de Velho (1979; 1981), Rêgo (1999), Emmi (1999), Emperaire \& Lescure (2000), Porto-Gonçalves (2001), Hébette (2004) e Castro (2010).

Embora não se possa considerar como únicas formas de atuação sobre a região, historicamente e de forma predominante, os modelos de Desenvolvimento pensado para a Amazônia pelos representantes do Estado pautaram-se na extração de produtos para exportação, tais como as drogas do sertão', a borracha (espécies de Hevea, principalmente seringueira - H. brasiliensis - e caucho - Castilla ulei), a castanha-do-Pará (Bertholletia excelsa), as madeiras e os minérios, desencadeando ciclos econômicos derivados de atividades extrativistas fomentadas pelos governantes e promovidas pelos detentores de poder político e econômico (Porto-Gonçalves, 2001; Hébette, 2004).

Apesar do fato de que cada uma dessas atividades causar distintos níveis de transformações no meio natural, dependendo da intensidade da exploração, da quantidade de pessoas e materiais envolvidos, das tecnologias disponíveis, etc., foi a partir dos anos 1970, com forte apoio estatal, que houve aumento na conversão das florestas para usos agrícola e pecuário. Esse processo foi estimulado em parte pela intensiva migração ocorrida na região nesse período e em parte por grandes projetos governamentais de fomento à produção agrícola e por obras de infraestrutura, como abertura de rodovias federais e estaduais, projetos de colonização e construção de hidrelétricas (Becker, 2005; Costa, 2012).

Recentemente, a crise ambiental mundial e suas inúmeras possibilidades, que de certa forma têm estimulado o reconhecimento da diversidade social que conforma a região amazônica, trouxeram à tona elementos novos à discussão sobre o Desenvolvimento dessa região, possibilitando um instigante dinamismo frente às ambiguidades inerentes aos discursos que colocam em um mesmo plano Desenvolvimento, Sustentabilidade e outros termos correlatos. Tornou-se recorrente no discurso de acadêmicos e de porta-vozes do governo, de movimentos sociais e de empresas, a necessidade

\footnotetext{
${ }^{1}$ Especiarias encontradas nas matas brasileiras e de grande valor no mercado europeu nos séculos XV, XVI e XII.
} 
do repensar o uso da biodiversidade, agregando valor aos produtos extrativistas e valorizando o conhecimento tradicional dos povos da floresta (Porto-Gonçalves, 2001; Lira et al., 2009; Porro \& Shiraishi Neto, 2013).

Diante desse contexto, por meio deste trabalho objetiva-se discutir o lugar do extrativismo vegetal no cenário do Desenvolvimento, considerando as diferentes perspectivas sobre essa atividade na Amazônia brasileira ${ }^{2}$. A discussão apresentada é pautada em revisão de literatura e em dados secundários sobre a atividade extrativista na região amazônica, corroborando as discussões sobre as imbricações existentes na relação entre exploração dos recursos naturais florestais e Desenvolvimento.

$\mathrm{O}$ texto segue estruturado em quatro seções, além desta introdução. Na primeira, é feita breve apresentação sobre a temática extrativismo no intuito de situá-la no debate acadêmico e no contexto das políticas públicas. Na segunda, aborda-se o uso dos recursos naturais a partir da realização de atividades econômicas ao longo do processo de ocupação da região amazônica, posicionando o extrativismo nos diferentes momentos da história. A partir da discussão iniciada nas seções anteriores, na terceira discute-se o extrativismo no contexto atual das estratégias de Desenvolvimento para a Amazônia brasileira. Em seguida, o trabalho é concluído com as considerações finais.

\section{O extrativismo interpretado por abordagens distintas}

O termo extrativismo tem diversidade semântica, conforme os autores que o utilizam. Emperaire
\& Lescure (2000), por exemplo, diferenciam o extrativismo de atividades de coleta por considerarem que estão relacionadas a lógicas econômicas diferentes. Com base em Homma (1992; 1993), Costa (2010) classifica a atividade extrativa em extrativismo de coleta e extrativismo de aniquilamento. No extrativismo de aniquilamento. "o trabalho do extrator 'anula' as propriedades originais do ecossistema, tomando suas partes, seus componentes estruturais como estoque de matérias independentes e genéricas (a madeira, a raiz, etc.)" (Costa, 2010, p. 8). Já o extrativismo de coleta "supõe a preservação da natureza originária, dado que é a produtora, no exercício de suas funções reprodutivas, dos valores-de-uso, que, como um fluxo, são colhidos por ação imediata do trabalho do extrator" requerendo o conhecimento dos processos naturais originais (Costa, 2010, p. 9).

No debate acadêmico, há duas principais abordagens sobre o a importância do extrativismo, principalmente no cenário amazônico: uma derivada da corrente que discute o extrativismo a partir da sua importância para a economia, supondo o desaparecimento da atividade extrativista devido a sua inviabilidade econômica; e outra cujos autores analisam as atividades extrativistas como pilar do modo de vida das populações locais.

Afiliados à primeira abordagem, Homma (1992; 2012) e Costa (2012) fazem sua leitura sobre o extrativismo vegetal a partir da ótica do mercado e da racionalidade econômica e defendem que a economia extrativa tem dificuldade de se manter diante do crescimento do mercado, sendo necessário investir no cultivo de produtos extrativos.

De outro ponto de vista, outros autores, como Rego (1999), Porto-Gonçalves (2001), Witkoski

\footnotetext{
${ }^{2}$ Neste trabalho, compreende-se Amazônia brasileira como a área delimitada pelo Instituto Brasileiro de Geografia e Estatística (IBGE) como Amazônia Legal (área que corresponde à Região Norte, parte do Estado de Mato Grosso e do Estado do Maranhão).
} 
(2007) e Mota et al. (2011), discutem o extrativismo a partir de uma perspectiva menos produtivista e mais cultural. Esses autores ressaltam que esta atividade não pode ser analisada somente a partir da perspectiva econômica, uma vez que a atividade extrativista faz parte da conformação da vida social. As abordagens peculiares a esses últimos autores, apesar das diferenças, têm em comum destacar que o extrativismo se refere não apenas à gestão dos recursos naturais e ao uso da biodiversidade, mas também sobre o conhecimento tradicional dos povos e populações, pondo em relevo o papel dos mesmos para a conservação ambiental.

Sem ter a pretensão de se afiliar a alguma dessas correntes, mas claramente não divergindo desta segunda, Becker (2005) propôs que os anos 2000 seriam o momento de realizar uma revolução científica e tecnológica na Amazônia, com vistas ao melhor aproveitamento do potencial dessa região, valorizando a sua biodiversidade e a respeitando como uma região consolidada e importante para o desenvolvimento do país, e não mais a tratando como produto de demandas externas, isto é, como uma simples região de fronteira, produto do capitalismo predatório, que vê a natureza como um bem infinito.

Tendo em vista os objetivos e as afinidades dos autores deste texto, neste trabalho discutir-se-á o extrativismo a partir de estudos que abordam essa atividade no sentido mais amplo, como os de Witkoski (2007) e de Mota et al. (2011), afastando-nos das leituras que privilegiam a racionalidade econômica e instrumental. Em ambos os trabalhos, o termo extrativismo é utilizado para designar atividades de extração e coleta de produtos encontrados na natureza (não cultivados), sejam elas predatórias ou não, voltadas para trocas econômicas ou simbólicas ou para o consumo familiar.

Ao longo do tempo, tal atividade tem propiciado o desenvolvimento de uma economia extrativista originária de ciclo econômico (Homma, 1992; 2012), como ocorreu no caso da exploração do pau-brasil, das drogas do sertão, da borracha, do minério e da madeira. Nesse contexto, o extrativismo dos recursos naturais se constituiu em muitas regiões do Brasil como a base para alavancar o Desenvolvimento Econômico dos territórios. Percebida como abundante e com possibilidade de mercado, a exploração extrativista dos recursos naturais demarcou fortemente certos períodos onde a economia se mostrou muito dinâmica em determinados espaços, expressando a perspectiva intervencionista que associava crescimento econômico e desenvolvimento ${ }^{3}$.

Na Região Norte, o investimento em atividades extrativistas mercantis de grande escala começa a mudar a partir da Segunda Guerra Mundial. Com o avanço das tecnologias de cultivos vegetais, da expansão da pecuária e da criação de sintéticos, o extrativismo foi perdendo importância na economia nacional. Tal atividade econômica ressurge na década de 1970, quando os seringueiros do Acre começaram a reivindicar o direito territorial e de uso dos produtos da floresta frente à expansão de fazendas de gado sobre áreas onde repousava sua economia (Emperaire \& Lescure, 2000).

Todavia, diante do reconhecimento do fracasso (tanto em nível social quanto ecológico) dos projetos de desenvolvimento que vislumbravam o

\footnotetext{
${ }^{3}$ O paradigma desenvolvimentista que prevaleceu nos últimos séculos, principalmente desde o final do século XIX, considera que Desenvolvimento resulta da associação entre progresso técnico e crescimento econômico, justificando o avanço do capitalismo no campo (Velho, 1981; Castelar, 2009). Tal paradigma é inspirado nas teorias econômicas que de forma geral consideram que, tal como resume Castelar (2009, p. 9), "uma estratégia de desenvolvimento é uma 'visão' de para onde se quer levar a economia”.
} 
crescimento econômico do país, a partir dos anos 1980 a diversidade social, o meio ambiente e a necessidade de participação da sociedade foram temas que passaram a ser considerados importantes no debate sobre Desenvolvimento, principalmente para dar visibilidade às lutas das populações locais (Acselrad, 2001).

Neste mesmo período, em nível mundial as problemáticas ambiental (como desmatamento, poluição das águas e efeito estufa) e social (desigualdade e fome) fomentaram a emergência de movimentos sociais que questionavam o modelo de desenvolvimento hegemônico no mundo e propunham um novo modelo pelo viés da sustentabilidade. Os discursos da sustentabilidade atingiram o centro da política ambiental internacional, dando visibilidade às diferenças espaciais e sociais no mundo (Sachs, 2001; Redclift, 2002).

Nesse contexto, as populações extrativistas (seringueiros) do Estado do Acre tiveram participação preponderante na retomada da importância do extrativismo na economia brasileira, mas a partir de um novo olhar, agora considerando as dimensões ecológica e social na realização da atividade extrativista. A reivindicação dos seringueiros pelo seu reconhecimento enquanto categoria social geograficamente situada resultou na criação da primeira Reserva Extrativista ${ }^{4}$ (RESEX) em território brasileiro em 1990, após o assassinato do líder seringueiro Chico Mendes por fazendeiros da região de Xapuri, no Estado do Acre. Com esse evento, o extrativismo foi perdendo a conotação negativa de atividade predatória e passou a ser pensado como possibilidade de valorização econômica da floresta aliada à conservação, embora em outras situações ainda seja significativo associar extrativismo a arcaísmo e atraso.

De todo modo, a partir da experiência da criação da RESEX Chico Mendes, na década de 1990, foi ampliado o investimento estatal na criação de áreas protegidas (Terras Indígenas - TI e Unidades de Conservação - UC) e programas de inclusão social das populações extrativistas. A inclusão de questões ambientais e de demandas de populações tradicionais na agenda política brasileira, além de ampliar a participação de diversos segmentos sociais no debate sobre extrativismo, tem resultado em mudanças na proposição de políticas intervencionistas (Acselrad, 2001). Nesse contexto, a criação das unidades de conservação, principalmente de RESEX's, é vista pelos ambientalistas conservacionistas como estratégias de ordenamento territorial para a conservação da biodiversidade e dos modos de vida das populações tradicionais.

Todavia, Homma $(1993$; 2012) contesta a possibilidade da criação das reservas extrativistas dinamizar a economia e promover o desenvolvimento econômico das populações extrativistas, uma vez que o extrativismo tradicionalmente realizado por essas populações é obsoleto por não disporem de tecnologias que permitam a produção em escala. Com a criação das RESEX's, o extrativismo passa a ser visto como possibilidade de utilização sustentável dos recursos naturais, mas é preciso haver investimento governamental para que a produção extrativista nessas unidades de conservação tenha índices satisfatórios de produtividade para manter a competitividade de mercado, uma vez que os produtos oriundos do extrativismo têm potencial de comercialização. Para Homma (1993; 2012), o

\footnotetext{
${ }^{4}$ Segundo Empereire \& Lescure (2000, p. 15), "trata-se de áreas concedidas de forma coletiva a grupos que vivem tradicionalmente da exploração dos produtos das florestas”.
} 
desafio está em conciliar a manutenção da estrutura da floresta natural com a elevação da produtividade das espécies exploradas.

Atualmente, no território brasileiro estão demarcadas 310 unidades de conservação federais geridas pelo Instituto Chico Mendes (ICMBio). Destas, 107 estão situadas na Amazônia. Conforme disposto no Sistema Nacional de Unidades de Conservação - SNUC (Brasil, 2002), as UC's são divididas em dois grandes grupos: o de Proteção Integral e o de Uso Sustentável. Neste segundo grupo, estão inseridas as RESEX's e as Reservas de Desenvolvimento Sustentável (Brasil, 2002). Ainda no âmbito da política de ordenamento territorial, como forma de conter os impactos ambientais derivados da expansão da fronteira agrícola, principalmente o aumento do desmatamento, na última década o governo federal criou as modalidades de assentamento Projeto de Desenvolvimento Sustentável (PDS) e Projeto Agroextrativista (PAE), privilegiando a dimensão extrativista do modo de vida das famílias assentadas.

Soma-se a essas medidas a pressão internacional pela conservação e pela preservação da floresta amazônica iniciada no final dos anos 80. Em 1992, por meio da Agenda 21, elaborada durante a Eco 92 no Rio de Janeiro, foi estabelecido um conjunto de mecanismos institucionais internacionais para tratar os problemas ambientais de forma mais eficiente. Em 2009, na Conferência de Copenhague, o governo brasileiro assumiu compromisso internacional de diminuir as emissões de $\mathrm{CO}_{2}$ com a redução do desmatamento da Amazônia (Redclift, 2002).

Nesse cenário de contradições, onde há a busca pela conexão entre geração de renda e conservação, a exploração de produtos extrativistas é vista como uma possibilidade de melhoria da qualidade de vida, não somente dos extrativistas e dos amazônidas, como também de toda a população brasileira, por conter o desmatamento e dinamizar a economia. No entanto, isso não é consenso. Homma (1992; 1993; 2012) e seus afiliados defendem que o extrativismo vegetal por si só não promoverá a inserção das populações amazônidas na sociedade capitalista, sendo mais estratégico focar na domesticação das plantas que sustentam o extrativismo. Para esse autor, o foco na conservação ambiental sem uma discussão profunda sobre geração de renda na região amazônica gera altos custos sociais por coibir o desenvolvimento de atividades econômicas mais rentáveis.

Como dito antes, essa visão contrasta com a de muitos outros autores, para os quais o desenvolvimento da região passa, necessariamente, pela valorização dos recursos naturais e pelas dinâmicas que são inerentes às populações extrativistas. Vale lembrar que, assim como destacou Aubertin (2000, p. 23), ao afirmar que "a história da Amazônia é indissociável da história do extrativismo", há quem defenda que o futuro também depende da forma como as dinâmicas extrativistas serão consideradas, conforme será discutido no próximo tópico.

\section{O extrativismo no cenário Amazônico: entre o desenvolvimento econômico e o desenvolvimento sustentável}

Na leitura de Porto-Gonçalves (2001), a Amazônia é uma região extremamente complexa e diversificada, ao contrário da visão externa que se tem sobre ela e que a classifica como homogênea, atrasada e como reserva de recursos. Para este autor, assim como para Hébette (2004) e Castro (2010), a imagem de "local não civilizado", de "vazio demográfico" e de natureza exuberante embasou, principalmente em meados do século XX, a projeção de um modelo de desenvolvimento pautado 
na exploração dos recursos naturais e cujo foco da atividade econômica era os produtos extrativistas. Dessa forma, historicamente os ciclos econômicos inerentes à ocupação recente da Amazônia derivam de atividades extrativistas fomentadas em grande parte pelo Estado, a partir do objetivo de promover o desenvolvimento econômico regional, integrando-a ao restante do país e ao comércio internacional.

No Brasil colonial e imperial, as migrações para o centro e para o norte do país derivaram de expedições que objetivavam a expansão e a proteção do domínio português sobre o território brasileiro com fins de exploração das drogas do sertão. Na Amazônia brasileira, as missões jesuítas e as expedições que objetivavam a exploração dos recursos naturais como atividades econômicas são fatos iniciais estruturantes da colonização e do início da formação social dessa parte do Brasil (Aubertin, 2000; Porto-Gonçalves, 2001). Desse modo, a ocupação da Amazônia se deu em várias levas de colonização, associadas à procura de recursos naturais economicamente exploráveis, fosse para o extrativismo ou para a expansão agrícola, o que resultou na atual estrutura social e territorial da Amazônia (Aubertin, 2000; Witkoski, 2007).

Nos séculos XVII e XVIII, a exploração das drogas do sertão conformou o sistema econômico em alternativa à implantação do projeto colonial baseado na economia de plantation, como acontecera em estados das regiões Nordeste e Sudeste ${ }^{5}$ do país. Diante da constatação da equivalência de produtos da floresta às especiarias procedentes do Oriente, os colonizadores passaram a investir na coleta de especiarias florestais, exportando-as ao mercado europeu, caracterizando os chamados ciclos extrativistas (Porto-Gonçalves, 2001; Costa, 2010).

O extrativismo das drogas do sertão registra a primeira atividade de exploração dos recursos naturais na Amazônia. De acordo com Porto-Gonçalves (2001, p. 81), a partir do "devassamento da floresta em busca de especiarias", iniciaram se o "(des)envolvimento da Amazônia e a valorização seletiva de seus recursos naturais". Focando nessa atividade, a administração colonial e as ordens religiosas passaram a estabelecer um diversificado sistema de caça, pesca e coleta. "Ao longo das várzeas emerge um sistema, que combina o extrativismo da floresta, a pesca e a agricultura, articulado, por meio dos regatões ${ }^{6}$, com as vilas e cidades" (Porto-Gonçalves, 2001, p. 82). Por essas características, Porto-Gonçalves (2001) considera que o extrativismo permaneceu como atividade socialmente importante para a região.

A opção pela coleta das drogas do sertão reconfigurou a estrutura do sistema mercantil vigente, que passou a ter como pilares a extração de recursos naturais - transformados em mercadoria - e a utilização da mão de obra indígena, posto que tal atividade exigia conhecimento aguçado sobre o ecossistema amazônico, além de ser inviável controlar escravos em meio às florestas - o que tornava ineficientes tanto o escravo africano quanto o colonizador europeu (Costa, 2010).

Apesar da importância econômica da atividade, o mercado para as drogas do sertão foi garantido até o século XVIII, quando "a queda da demanda, a rarefação dos produtos nos locais mais acessíveis em consequência de uma superexplora-

\footnotetext{
${ }^{5}$ Segundo Costa (2010), as condições do ecossistema amazônico tornaram limitante a reprodução do sistema de produção agrícola que se tinha em outras partes do país (cultivo de cana-de-açúcar utilizando mão de obra escrava).

${ }^{6}$ Os regatões são comerciantes que navegavam em pequenas embarcações pelos rios e igarapés da região amazônica oferecendo mercadorias à população (Emmi, 1999; Aubertin, 2000; Porto-Gonçalves, 2001).
} 
ção e os esforços da administração para encorajar a agricultura marginalizaram, pouco a pouco, o extrativismo" (Aubertin, 2000, p. 24). No entanto, no século seguinte o extrativismo continuou a movimentar a economia regional (Kupfer, 2010). Porto-Gonçalves (2001) relata que em 1830 eram exportados sapatos e tecidos emborrachados a partir da borracha amazônica, principalmente para os Estados Unidos. A atividade de seringa reformatou a dinâmica econômica da região amazônica, atraindo migrantes nordestinos retirantes da seca e investimento da oligarquia local e de estrangeiros. $\mathrm{O}$ avanço das indústrias automobilística e pneumática e da química, em meados do século XIX, provocou aumento da demanda internacional por borracha, incrementando a extração deste produto.

A descoberta de espécies mais produtivas levou ao deslocamento das áreas de extração situadas no Baixo Amazonas e região das ilhas paraenses, nas proximidades de Belém, para os altos cursos dos rios Tapajós, Xingu, na Amazônia Oriental, e para os altos cursos dos rios Purus e Juruá, na Amazônia Ocidental (Porto-Gonçalves, 2001). A expansão das áreas de extração de borracha favoreceu o povoamento da região e conformou a organização social a partir do sistema de aviamento 7 , "que se sustentava em relações clientelistas por todo o vale amazônico" (Porto-Gonçalves, 2001, p. 86). Essa atividade favoreceu a estruturação de vias de escoamento do produto, como a estrada de ferro Madeira-Mamoré.

No início do século XX, o Brasil deixou de dominar o mercado da borracha, em função da produção asiática ${ }^{8}$, levando ao declínio da fase áurea da borracha no início da década de 1900, desestru- turando e estagnando as economias que cresceram em função dessa atividade, cedendo lugar para produtos esquecidos economicamente (Aubertin, 2000), mas sempre presentes no cotidiano dos seringueiros, como a castanha-do-Pará, produto que deu continuidade à prática de aviamento e passou a movimentar a economia extrativa em lugares de ocorrência de castanheiras, como no Pará.

Na década de 1920, em locais onde ainda se extraía látex, o governo brasileiro passou a fomentar o cultivo de seringueiras no intuito de sustentar a exportação da borracha para retomar o desenvolvimento econômico da região amazônica. Houve investimento do capital privado na expansão dos seringais, a exemplos da Companhia Ford Industrial do Brasil (criada por Henry Ford) e do Banco de Crédito da Borracha (criado pelo governo americano). Esse investimento favoreceu o segundo ciclo da borracha, que ocorreu no período da Segunda Guerra Mundial, quando se fecharam as portas para a exportação de borracha asiática. Contingentes humanos foram "recrutados" para os seringais principalmente nordestinos -, mas o investimento americano na atividade durou pouco tempo, pois, com o fim da Guerra, o mercado internacional voltou a se abrir para os asiáticos. Além disso, a fabricação de borracha sintética foi determinante para a redução da exportação.

Com o novo declínio da exploração de látex, em 1948 foi criada a Superintendência do Plano de Valorização Econômica da Amazônia (SPVEA), no intuito de promover a integração da região à economia nacional a partir do incentivo a atividades que movimentariam a economia, voltando-se

\footnotetext{
${ }^{7} \mathrm{O}$ aviamento se caracteriza como sistema de venda de mercadorias a crédito baseado no escambo, onde o comerciante (seringalista) adianta bens de consumo, instrumentos de trabalho e alimentos para os trabalhadores (seringueiros) e recebe o pagamento com produtos extrativistas ou agrícolas (Emmi, 1999; Aubertin, 2000; Porto-Gonçalves, 2001).

${ }^{8}$ Os ingleses aclimataram as sementes brasileiras e investiram em plantios no sudeste asiático (Aubertin, 2000).
} 
para o financiamento da exploração da borracha (Ferreira, 1989).

A partir dos anos 1960, as ações do Estado passam a ser as grandes motoras do fluxo migratório para a região amazônica, na perspectiva de movimentar a economia nacional. Em 1966, a SPVEA foi substituída pela Superintendência do Desenvolvimento da Amazônia (SUDAM), órgão criado com o mesmo intuito, mas com estratégias diferentes, voltadas à expansão da pecuária e à exploração mineral devido à descoberta de jazidas minerais e à abertura do garimpo em Rondônia e no Pará (Ferreira, 1989). Isso resultou, anos mais tarde, no aumento de latifúndios e na implantação de grandes empreendimentos de exploração de minérios por investidores externos (Hébette, 1991; Porto-Gonçalves, 2001).

Hébette $(1991 ; 2004)$ aponta que as ações estatais representavam as estratégias do Governo Militar para sanar diversos problemas nacionais, em especial a concentração demográfica e as crises econômicas no Nordeste e no Centro-sul do Brasil ${ }^{9}$. Um dos focos do Governo era a expansão da fronteira agrícola e para tal se fazia importante "a implantação dos grandes eixos rodoviários para estimular a mobilidade e a circulação de pessoas e mercadorias" (Hébette, 1989, p. 10). A colonização oficial da Rodovia Transamazônica realizada pelo Governo Militar na década de 70 e também os chamados Projetos Integrados de Colonização (PIC) atraíram migrantes para a região de fronteira agrícola amazônica.

Na leitura de Lira et al., (2009), a estratégia de desenvolvimento para a Amazônia até a década de 1980 seguiu uma lógica espacial e setorial de acordo com as características regionais, sendo privilegiada a geração de produtos extrativistas e agrícolas. Outros programas estatais foram complementares à estratégia de dinamização econômica e de integração amazônica, como o Programa de Polos Agropecuários e Agrominerais da Amazônia (Polamazônia) cujo objetivo foi articular os eixos viários aos projetos de desenvolvimento setorial (Lira et al., 2009).

A garantia do governo brasileiro para implantação dos programas e projetos foram os investimentos em obras de infraestrutura para viabilizar o escoamento da produção e subsídios e incentivos fiscais e financeiros para fomentar o investimento de grandes empresas na implantação de indústrias e de fazendas, favorecendo explicitamente a apropriação da Amazônia por uma lógica capitalista (Porto-Gonçalves, 2001; Hébette, 2004; Lira et al., 2009). A mineração, por meio da implantação do PGC, constituiu-se como atividade de atração de uma nova frente de migração, sem, no entanto, reduzir as características agropecuárias da fronteira (Hébette, 2004).

Concomitante à implantação dos grandes projetos (Hébette, 2004), a disponibilidade de florestas exerceu um importante atrativo para madeireiras do Sudeste e do Sul do país. A abertura das estradas propiciou a implantação de empresas madeireiras em busca de madeiras de alto valor econômico, dando início à exploração da madeira por meio de um sistema de serrarias itinerantes ${ }^{10}$. A instalação de serrarias não só atraiu pessoas em

\footnotetext{
${ }^{9}$ Dentre essas ações, são citadas pelo autor a construção de vias de comunicação, como ferrovias e rodovias, a criação da SUDAM e a implantação de grandes projetos, a exemplo da construção de hidrelétricas em Rondônia, Tocantins e Pará e do projeto Jarí e de outros vinculados ao Programa Grande Carajás (PGC).

${ }^{10}$ As madeireiras eram implantadas em locais com oferta de madeira de valor comercial. À medida que as espécies exploradas economicamente acabam em determinado local, havia migração de madeireiras para áreas novas com madeira em abundância.
} 
busca de empregos, como também movimentou a economia e fomentou a interiorização da colonização por meio do acesso à terra por parte de famílias agricultoras devido à abertura de ramais madeireiros em áreas de terras devolutas. Nessa época, o extrativismo vegetal pautado na exploração madeireira fomentou a ocupação das áreas de floresta por famílias migrantes de diversas regiões do país.

Na década de 1980, além da exploração madeireira, a construção de grandes empreendimentos ${ }^{11}$ somou-se à abertura de rodovias, tornando-se outro atrativo para os migrantes. Durante essas décadas, a interferência do governo resultou primeiramente em mudanças nas estruturas social e produtiva da região, tendo em vista que a economia regional, até então centrada no extrativismo vegetal, passou a ser diversificada, havendo expansão do setor de mineração, de serviços e do campesinato.

Apesar de, no geral, o extrativismo, enquanto atividade motora da economia na Amazônia, estar associado ao "progresso" e ao desenvolvimento econômico, a presença do movimento ambientalista nos debates políticos referentes à região amazônica e a luta das categorias sociais locais, como os seringueiros, têm influenciado novas ações de intervenção nessa região. $\mathrm{O}$ cenário começou a mudar no final dos anos 1980, quando começaram a ganhar força novas formas de interpretar a natureza, havendo o reconhecimento de agentes sociais como povos da floresta (o que antes trazia uma conotação negativa).

Se no âmbito da lógica desenvolvimentista/ econômica hegemônica o extrativismo é visto como atividade geradora de lucro. Todavia, desde o início da colonização as famílias que vêm ocupando a região amazônica e desenvolvendo atividades agrícolas realizam o extrativismo de produtos voltados para o consumo familiar e venda esporádica. Seguindo a lógica de reprodução social, o extrativismo faz parte do cotidiano das famílias camponesas como fonte de alimentos, de ervas medicinais, de material de construção e de geração de renda ${ }^{12}$. Este assunto tem despertado diversos interesses, gerando discussões e tratativas em nível internacional e envolvendo diversos organismos multilaterais, como a Organização das Nações Unidas para a Educação, a Ciência e a Cultura (UNESCO), a Organização Mundial de Propriedade Intelectual (OMPI) e a Organização Mundial do Comércio (OMC) (Zanirato \& Ribeiro, 2007).

Entretanto, a forma como o extrativismo vem sendo desenvolvido pelas populações que conformam o tecido social da região amazônica é motivo de divergências entre pesquisadores e interventores a respeito da viabilidade da atividade extrativista. Para Homma (1992), essa é importante para a manutenção do modo de vida amazônido, mas é economicamente frágil. No entanto, com a atual valorização econômica de produtos florestais extrativistas que, até então, eram utilizados no consumo familiar ou para venda esporádica, evidenciou o extrativismo como atividade significativa na inserção das populações tradicionais ao mercado. Nesse sentido, o extrativismo tem sido discutido como alternativa às atividades que têm ocasionado o desmatamento, como exploração madeireira e expansão de atividades agrícolas, principalmente a pecuária.

\footnotetext{
${ }^{11}$ Tais como a construção da Usina Hidrelétrica (UHE) de Tucuruí e a conclusão das obras de implantação da Companhia Vale do Rio Doce (CVRD) em Carajás, no Pará.

${ }^{12}$ Em trabalhos que abordam o uso da floresta pelas populações residentes na Amazônia, quer sejam agricultores, ribeirinhos, indígenas, dentre outras categorias sociais, o extrativismo é apontado como atividade que permeia o modo de vida dessas populações (Velho, 1979; Emmi, 1999; Porto-Gonçalves, 2001; Witkoski, 2007).
} 
Mais do que discutir a viabilidade ou inviabilidade econômica e ambiental em nível das comunidades tradicionais, a problemática do extrativismo atualmente é estabelecida frente ao cenário de disputas pela ocupação do território e pela apropriação dos recursos naturais. As disputas ocorrem entre diversos atores nos âmbitos local, regional, nacional e internacional. São seringueiros, indígenas, quilombolas, ribeirinhos, assentados, posseiros, fazendeiros, empresas madeireiras, empresas mineradoras, usinas hidrelétricas, pesquisadores, agentes estatais, agentes de organizações não governamentais e outros segmentos sociais que coexistem e se inter-relacionam de diversas formas, buscando interesses distintos. São unidades federativas com características biofísicas e socioeconômicas diferentes, cujo tratamento é muitas vezes padronizado em função da visão homogênea que se tem da região amazônica.

Logo, a problemática do extrativismo engloba ainda os conflitos sociais em torno da disputa por recursos. Tal como apontam os trabalhos de Little (2004), Acselrad (2004) e Mota et al. (2011), os conflitos emergem de disputas entre grupos sociais que apresentam distintos tipos de relação com o meio natural onde vivem, tornando os recursos objetos de disputas onde suas bases de sustento estão ameaçadas. Segundo Almeida (2009), os conflitos sociais emergentes chamam atenção para a existência de uma diversidade social explicada pela heterogeneidade de formas de relação das comunidades com a natureza, havendo a "descoberta" de racionalidades múltiplas, o que torna controverso pensar no extrativismo na atualidade como atividade a seguir um modelo padrão.

\section{O extrativismo e as atuais estratégias de desenvolvimento para a Amazônia}

Na avaliação de Acselrad (2001), ao longo das décadas de 1980 e 1990 predominaram dois paradigmas antagônicos de desenvolvimento: um que adota a ideia globalizante de modernização e crescimento econômico e o outro que adota a cidadania como condição do desenvolvimento, descentralizando com vistas a elevar a autossuficiência microrregional (Acselrad, 2001) ${ }^{13}$. Nesse novo viés, torna-se estratégico pensar modos de produção agrícola menos dependentes e pautados no uso "sustentável" dos recursos endógenos e políticas públicas que reconheçam as especificidades locais (Acselrad, 2001). A perspectiva da sustentabilidade trouxe mudanças significativas no olhar da sociedade sobre o uso e a gestão dos recursos naturais. No entanto, ressalta-se que o desenvolvimento sustentável é um projeto global e difuso porque não incorpora a autoanálise dos indivíduos, uma vez que a mudança no comportamento humano reflete na relação que este estabelece com a natureza e vice-versa (Redclift, 2001).

Essa segunda abordagem baseia-se na sustentabilidade como estratégia de Desenvolvimento, inaugurada a partir do Relatório Brundtland e popularizada mundialmente com a realização da Conferência da ONU sobre Meio Ambiente e Desenvolvimento (UNCED), realizada no Rio de Janeiro em 1992, momento em que o tema do desenvolvimento sustentável passa a ser inserido oficialmente no discurso da maioria dos governantes mundiais (Brüseke, 2003).

\footnotetext{
${ }^{13}$ Tendendo a concordar com este segundo, ressalta-se que é preciso certo cuidado com essa autossuficiência em um país como o Brasil, em que o exercício da democracia econômica é recente (Homma, 2012), podendo representar um risco para o mau uso e a apropriação dos recursos naturais, a partir da diminuição do controle do Estado.
} 
Visto dessa forma, o extrativismo tem sido discutido como possibilidade de desenvolvimento para a Amazônia. No entanto, tal proposição é feita a partir de dois vieses distintos em suas aplicações, dinâmicas e efeitos: a) um associado diretamente a grandes empresas e empreendimentos privados, que propõe implantação de projetos relacionados à extração mineral e à exploração madeireira; e b) outro que toma como direcionamento a ideia de que o estabelecimento da cadeia de comercialização dos produtos extrativistas deve considerar a discussão sobre sustentabilidade e a inserção da produção extrativista e agrícola das populações tradicionais no mercado. Estes vieses apresentam diferentes formas de interação com o mercado.

Desta forma, o cenário atual sobre o desenvolvimento da Amazônia supõe o desafio de conciliar ações voltadas para o desenvolvimento econômico, construção de infraestrutura e combate à degradação ambiental. Na leitura de Almeida (2009, p. 86)

A finalidade das políticas de ocupação racional e de exploração racional dos recursos sugere uma reação à degradação; e quem teria provocado essa degradação seria o conhecimento primitivo, o conhecimento selvagem que não pode competir com a racionalidade das potências europeias [...]. A ação do Estado surge para valorizar o que degradou ou decaiu, daí a insistência em frisar a valorização da Amazônia.

É preciso considerar que a apropriação ambientalista da Amazônia ("amazonismo") é pautada em diversos discursos que categorizam essa região de acordo com a percepção que os grupos ambientalistas constroem sobre ela (Litle, 2004). De acordo esse autor, são duas as visões do imaginário social sobre a Amazônia: a) um lugar idílico; b) um lugar inóspito, perigoso e de difícil convivência para o ser humano ("inferno verde").
Essas visões vêm sendo construídas historicamente, pois a Amazônia sempre foi vista como um objeto de intervenção, ao invés de um lugar que pertence às pessoas que nela habitam. Tornou-se campo de disputa pelo acesso aos recursos naturais e pelo controle dos grupos sociais endógenos que são vistos de duas formas na discussão sobre gestão dos recursos naturais: como conservacionistas, pela forma de adaptação sustentável aos ecossistemas (indígenas e caboclos); ou como destruidores (garimpeiros, colonos, fazendeiros e madeireiros).

No geral, a discussão sobre gestão dos recursos naturais tem orientado a criação das unidades de conservação e de projetos de assentamento cujas normas regulam o uso da floresta. Nessa lógica, o extrativismo pode ser considerado uma atividade que tem a coletividade como pilar.

No contexto da criação das reservas e de projetos dessa natureza, a demarcação de áreas no âmbito do ordenamento territorial tem gerado divergências políticas e acadêmicas quanto à apropriação do território, tanto em relação aos aspectos legais de propriedade e acesso à terra como aos impactos da ação antrópica sobre o ambiente natural. Os defensores de uma exploração mais economicista e baseada nos grandes projetos consideram que tais medidas impedem o exercício do direito deles ao crescimento econômico e ao "progresso", enquanto os que comungam das ideias ambientalistas defendem a demarcação dos territórios como medidas alternativas e favoráveis à proteção ambiental e ao desenvolvimento sustentável.

No geral, a pressão externa nacional e internacional por ações estatais que freiem a expansão do desmatamento e a degradação ambiental, associada à pressão regional pela regularização fundiária diante dos conflitos sociais existentes, tem levado os formuladores de políticas a repensar o ordenamento territorial. No entanto, tais medidas têm causado 
conflitos envolvendo categorias sociais distintas, agentes estatais, acadêmicos ou pesquisadores e agentes vinculados a entidades por confrontarem interesses e por trazerem consigo o caráter restritivo ao livre acesso aos recursos naturais utilizados para o extrativismo e, consequentemente, à reprodução das práticas inerentes ao processo de coleta dos produtos.

A disputa pelos produtos das florestas (fauna e flora), das águas e do solo tem como principal característica o confronto entre o economicismo e o ambientalismo. Por isso, atualmente a discussão sobre o uso dos recursos naturais, em especial o extrativismo, remete a reflexões acerca do que seriam bens comuns e seus marcos regulatórios. Para isso, ainda é preciso avançar na compreensão acerca das particularidades das atividades extrativistas, dos direitos coletivos, dos regimes de propriedade e do futuro modelo de sociedade, conciliando as diferentes escalas de abordagens.
No entanto, isso não é tarefa fácil, principalmente quando, ao invés de confrontar interesses, é preciso convergi-los em modelos onde a sustentabilidade deve ser algo consensual. Nesse cenário, a discussão sobre o extrativismo reemerge como importante atividade para reprodução social das famílias e para a conservação da biodiversidade (Almeida, 1994). No entanto, apesar dos avanços, as pesquisas ainda são incipientes para subsidiar as discussões sobre o uso sustentável dos recursos naturais por meio do extrativismo. Além disso, não se pode generalizar o extrativismo como atividade promissora para toda a Amazônia. Parte significativa da população situa-se em locais com reduzida área de floresta. Nas Figuras 1 e 2 a seguir, são apresentados respectivamente os mapas de localização das unidades de conservação e da área desmatada atualmente na Amazônia brasileira. Comparando os mapas apresentados nas Figuras 1 e 2, observa-se que as áreas de UC's apresentam

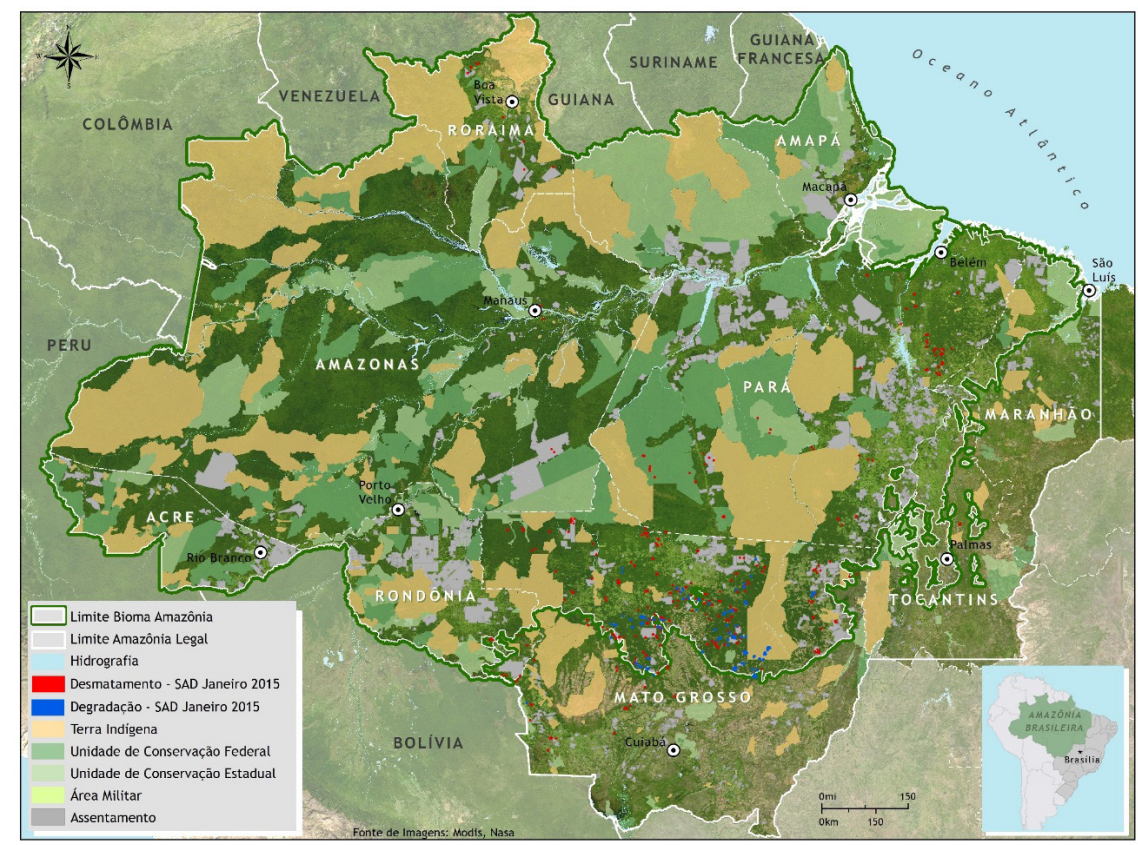

FIGURA 1 - Mapa da distribuição espacial das áreas protegidas na Amazônia brasileira.

FONTE: Fonseca et al. (2015, p. 10). 


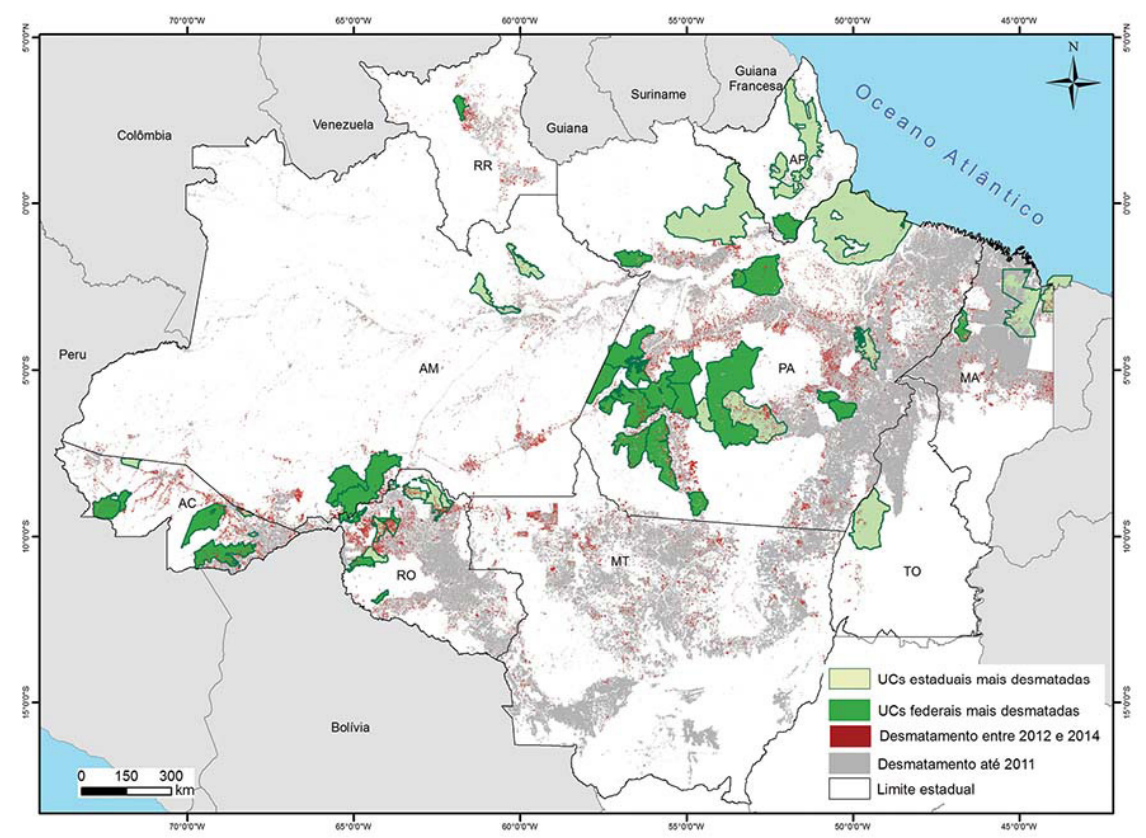

FIGURA 2 - Mapa ilustrativo do desmatamento na Amazônia. FONTE: Araújo et al. (2015, p. 20).

maior cobertura florestal que as áreas não demarcadas como de conservação ambiental. Já as áreas com maior índice de desmatamento situam-se nas áreas de expansão da fronteira agrícola onde estão localizados as estradas, os projetos de colonização e os projetos de assentamento. Segundo dados do Sistema de Informações de Projetos de Reforma Agrária - SIPRA (2012), na Região Norte, até o início de 2012, haviam sido assentadas 503.175 famílias, das quais quase $58 \%$ estão no Estado do Pará. Para Becker (2005), no contexto geopolítico caracterizado pela mercantilização da natureza, o desafio do desenvolvimento da região amazônica perpassa pelo fortalecimento político-econômico das comunidades tradicionais, moradores das áreas de florestas ainda existentes. Por isso, para a autora, o Estado deveria "substituir a política de ocupação por uma política de consolidação do desenvolvimento" (Becker, 2005, p. 83), uma vez que a Amazônia já está ocupada.
Frente à ocupação existente, a autora analisa que

São três as grandes frentes na Amazônia hoje: uma parte de São Felix do Xingu, Sudeste do Pará, em direção ao rio Iriri; outra parte do extremo Norte de Mato Grosso pela rodovia Cuiabá-Santarém, em torno de cuja pavimentação há grande discórdia, pois ela atravessa não mais a borda, mas o meio da floresta; a terceira parte do Norte de Mato Grosso e de Rondônia em direção ao Sul do Estado do Amazonas (Becker, 2005, p. 81).

Nas áreas desmatadas, torna-se desafiador abordar o extrativismo como alternativa econômica frente à atual situação de baixo percentual de florestas. Em vista disso, o extrativismo enquanto estratégia de desenvolvimento (geração de renda) para as milhares de famílias que vivem na Amazônia torna-se controverso da maneira como tem sido 
pensado - a partir do uso de produtos de florestas primárias. Logo, torna-se pertinente discutir o potencial do extrativismo vegetal e animal em áreas onde a cobertura vegetal é formada por diversos tipos de vegetação (natural e cultivada), ecossistemas e grupos sociais.

Outro fator importante a ser considerado é a dificuldade em contabilizar e valorar o incontável número de produtos extrativistas que são utilizados nessas áreas, bem como localizar e quantificar a produção, principalmente quando se considera o autoconsumo.

Os dados apresentados na Tabela 1, a seguir, ilustram a variabilidade de produtos extrativistas utilizados na Amazônia. De acordo com os dados do IBGE (2006), em termos quantitativos, são diversos os produtos extrativistas e a quantidade extraída, havendo expressiva diferença entre os

TABELA 1 - Produção dos principais produtos extrativista (tonelada) por estado da Amazônia Legal.

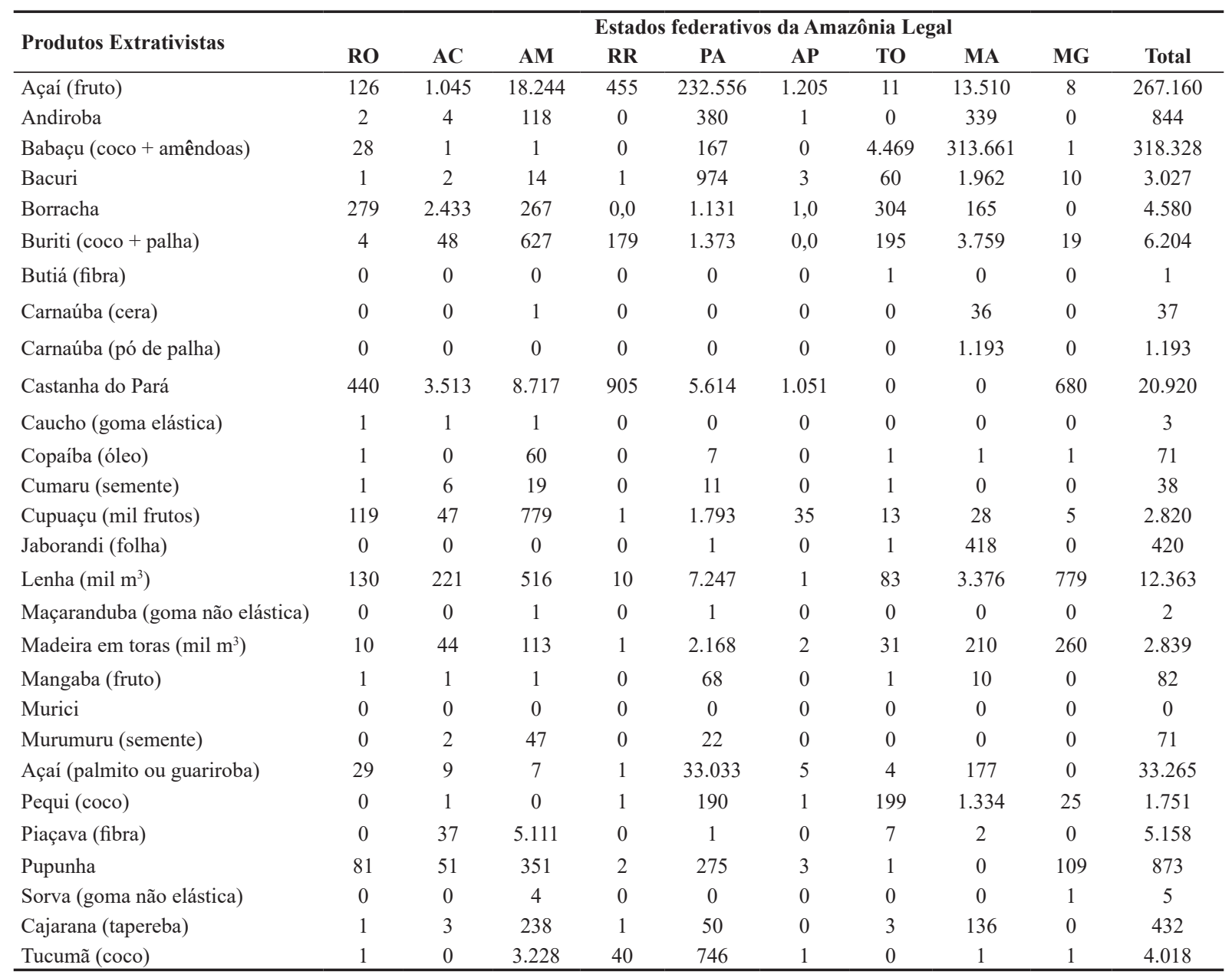

FONTE: Dados do IBGE (2006) 
estados amazônicos no que concerne à extração dos produtos extrativistas contabilizados no Censo Agropecuário de 2006.

De acordo com os dados apresentados na Tabela 1, os principais produtos extrativistas estão concentrados nos Estados do Pará (açaí, palmito, castanha-do-Pará, borracha e tucumã), Amazonas (piaçava, tucumã, castanha-do-Pará e açaí), Maranhão (babaçu, açaí e palmito), Acre (borracha e castanha-do-Pará) e Tocantins (babaçu) ${ }^{14}$.

Isso não significa dizer que não há extrativismo vegetal nos demais Estados e que são somente os produtos da floresta listados os utilizados pela população. No entanto, tais dados sugerem que os produtos e sua importância econômica (seja para consumo familiar ou para comercialização) diferem de estado para estado.

É possível supor que a extração de produtos vegetais diversos predomina nos estados com maior área territorial e onde anteriormente houve intervenção estatal fortemente voltada para a exploração dos recursos naturais. Em 2014, na Região Norte, foram coletadas 184.253 t de açaí, 35.974 t de castanha-do-Brasil e 1.522 t de borrachas (látex de seringueira e de caucho), além da extração de $10.231 .061 \mathrm{~m}^{3}$ de madeira em tora, $5.828 .077 \mathrm{~m}^{3}$ de madeira em lenha e 65.889 (t) de carvão vegetal (IBGE, 2014).

Alguns casos de cooperativismo e de ações coletivas têm representado uma alternativa de governança para liderar processos de organização da cadeia produtiva de produtos extrativistas em alguns estados, a exemplo das experiências desenvolvidas a partir da Cooperativa Central de
Comercialização Extrativista do Estado do Acre COOPERACRE - e da Cooperativa Mista da Flona do Tapajós - COOMFLONA.

A COOPERACRE, criada em $2001^{15}$, insere-se, principalmente, na tradicional atividade da cadeia produtiva da castanha-do-brasil. Aos poucos, passou a assumir a comercialização da castanha-do-brasil, além de borracha (nativa e de cultivo), óleo de copaíba e polpa de frutas. Reúne, atualmente, 25 cooperativas e associações, distribuídas em 10 municípios situados no Acre, abrangendo em torno de 1.800 famílias extrativistas. É a cooperativa referência em relação à produção extrativista do estado, que visa ao beneficiamento e comercialização, reunindo os principais atores de apoio à cadeia de valor da castanha-do-brasil (Pires \& Alves, 2009).

A COOMFLONA, cooperativa formada exclusivamente pelos comunitários da Floresta Nacional do Tapajós, situada no Estado do Pará, executa o manejo florestal conforme o Plano de Manejo Florestal de Uso Múltiplo na Floresta Nacional do Tapajós. Destaca-se que a atividade econômica de produção madeireira é a mais importante realizada por estas comunidades da Flona do Tapajós, movimentando R\$ 4 milhões/ano a partir da comercialização de madeira em tora. De acordo com Espada \& Sobrinho (2015), atua como geradora de trabalho e renda para 212 cooperados, impactando na qualidade de vida de aproximadamente 5.000 moradores, por meio de fundos oriundos da venda da madeira.

Em ambas as experiências - cooperativas de exploração e comercialização de produtos extrativistas -, as parcerias entre diversos atores

\footnotetext{
${ }^{14}$ Pinto et al. (2011) estimam que no segundo semestre de 2011 apenas em Belém, Pará, a comercialização de PFNM in natura gerou receita bruta superior a R \$ 37,7 milhões, dos quais 97\% correspondem à venda do açaí. Os outros 3\% são faturamentos gerados pela comercialização de pupunha, cupuaçu, castanha-do-Pará, taperebá e andiroba.

${ }^{15}$ A COOPERACRE tem "como missão organizar, representar e garantir a produção extrativista, valorizando o produtor e promovendo a igualdade social, econômica e ambiental” (Pires \& Alves, 2009, p. 11).
} 
foi fundamental para articular as atividades. $\mathrm{Na}$ análise de Espada \& Sobrinho (2015), as parcerias são uma forma de desenvolver uma governança ambiental cooperativa, fortalecendo a ação local e a gestão compartilhada dos recursos, como, por exemplo, as florestas públicas amazônicas. Para os autores, as parcerias com esse objetivo podem favorecer um manejo florestal comunitário como uma ação coletiva e aumentar a eficácia dos programas e projetos de desenvolvimento local. Neste caso, destacam a parceria entre a COMFLONA e instituições governamentais e não governamentais para o manejo florestal comunitário.

Cabe ressaltar, ainda, as diversas possibilidades do manejo de Produtos Florestais Não Madeireiros - PFNM, termo utilizado para caracterizar aqueles materiais de origem biológica (vegetal ou animal) que não sejam a madeira, mas que sejam extraídos de florestas naturais ou nativas e que tenham uma finalidade para a sociedade ${ }^{16}$. Estes produtos, pela lógica social e ambiental, podem prover uma economia florestal sustentável, desde que insiram as pessoas em cadeias de valor localizadas. Para tanto, é estratégico que as comunidades tradicionais sejam envolvidas no processo e que seja planejado manejo adequado a estes sistemas, inclusive devido o fato de estes produtos terem uma utilização doméstica, comercial, e ainda representarem significados sociais, culturais ou religiosos.

Além do mais, é preciso considerar que, apesar de o extrativismo ser inerente à formação social da região amazônica, ao longo do tempo esta vem deixando de ser a única ou principal atividade (como na época da borracha) para ser inerente a outras, como a agricultura e a criação de pequenos animais (Witkoski, 2007). Também, há de se considerar, como lembrou Kupfer (2010), que o boom do extrativismo, nos séculos XVIII e XIX, quase sempre produziu consequências negativas à produção agrícola, que tende a ser deixada de lado, no que diz respeito aos investimentos de força de trabalho e também em termos de investimentos públicos e privados. Por isso, sua realização depende de alguns fatores, como o calendário das atividades agrícolas, força de trabalho disponível, mercado, ciclo das águas, dentre outros (Emperaire \& Lescure, 2000; Witkoski, 2007).

Isso se torna mais complexo quando as análises feitas por disciplinas individualizadas em relação ao meio ambiente tornam-se questionáveis (Redclift, 2001). Seguindo as reflexões deste autor, é preciso questionar até que ponto a ciência tem como valorar o meio ambiente e apontar os caminhos para uma gestão ambiental mais adequada, quando a própria ciência é estabelecida a partir de paradigmas que também são socialmente construídos, representando uma determinada visão sobre desenvolvimento e sobre o meio ambiente e sobre sua gestão. Redclift (2001) sugere a necessidade de integração entre os campos disciplinares distintos (ciências sociais e naturais) para que seja feita reflexão mais equilibrada a respeito da gestão dos recursos naturais.

Apesar das mudanças, hoje o conhecimento científico ainda é um norteador da intervenção estatal e por isso é também um campo de disputas, mas que incorpora novos atores e supõe novas estratégias de cooperação internacional e mudanças nos padrões de pesquisa e de intervenção do Estado na Amazônia. Segundo Almeida (2009), as estratégias

\footnotetext{
${ }^{16}$ Destacam-se produtos como plantas medicinais e de uso alimentício, fibras, óleos, látex, resinas, entre outros (Soares et al., 2008; Paes-de-Souza et al., 2011; Elias \& Santos, 2016).
} 
de ação estão mudando, apontando que seria interessante utilizar ações em rede. É importante pensar, então, quem são os atores envolvidos na ação ambiental na Amazônia, qual o papel de cada um e como são articulados. Almeida (2009) aponta para mudanças do sujeito da ação ambiental: os grupos sociais se autodefinem, surgindo novas categorias sociais e políticas, formando movimentos sociais, que passam a ser o sujeito da ação e não mais um produto da natureza, ou, como informam Porro \& Shiraishi Neto (2013, p. 306), "sujeitos de direitos: direitos emergidos das práticas sociais locais e das lutas políticas em sua defesa".

Já Litlle (2004) traça os seguintes elementos como cenários futuros no debate sobre desenvolvimento para a Amazônia: produção científica ainda biocêntrica, mas focada para a genética (estudos sobre a biodiversidade); grupos locais fortalecidos e com expressão política, incorporando em suas ações o discurso ambientalista; conflitos envolvendo biopirataria e apropriação do conhecimento; alianças e parcerias entre povos da Amazônia e movimento ambientalista em prol da proteção do meio biofísico amazônico.

Longe de ser algo simples de planejar e executar, tais estratégias deveriam emergir de um amplo debate sobre os conceitos que orientam sua formulação, tendo em vista o entrelace entre estratégias políticas e interesses acadêmicos. Seguindo as reflexões de Almeida (2009), o primeiro passo seria superar a característica histórica da intervenção estatal na Amazônia: pautada em esquemas interpretativos desenvolvidos pelo pensamento erudito (cientistas) em relação à natureza que sugeriam uma abordagem dualista de modalidades vistas como oposição simétrica (progresso e atraso, civilização e vida selvagem, etc.). Para Becker (2005, p. 85), "a floresta só deixará de ser destruída se tiver valor econômico para competir com a madeira, com a pecuária e com a soja", por isso, o Estado tem papel fundamental na viabilização de "uma revolução científico-tecnológica na Amazônia que estabeleça cadeias tecnoprodutivas com base na biodiversidade, desde as comunidades da floresta até os centros da tecnologia avançada" (Becker, 2005, p. 85). Para tanto, tal como defendido pela autora, "é necessário articular os diferentes projetos e os diversos interesses e conflitos que incidem na região" (Becker, 2005, p. 83).

\section{Considerações finais}

As estratégias de desenvolvimento para a Amazônia brasileira têm sido configuradas a partir da perspectiva de integração econômica dessa região às economias nacional e internacional a partir da transformação de suas riquezas naturais em mercadorias. Nesse cenário, o extrativismo vegetal tem sido projetado ora como possibilidade de desenvolvimento econômico, ora como possibilidade de conservação dos recursos naturais e do modo de vida das populações amazônidas, dependendo das matrizes interpretativas e propositivas que constituem os distintos projetos.

Recentemente, as interfaces entre atores têm resultado em diversos programas e políticas governamentais, como, por exemplo, os relacionados à gestão dos recursos naturais por parte dos diversos grupos sociais. Tais programas e políticas parecem traçar uma linha tênue entre demandas sociais locais e demandas globais, tendo em vista que devem resultar do amplo debate entre pesquisadores, agentes estatais e população local, atores igualmente importantes no processo de desenvolvimento.

No entanto, constata-se a complexidade das questões e os diversos conflitos que delas emergem. O paradigma que tem orientado o direcionamento 
da exploração dos recursos naturais - em seu sentido de aniquilamento ou por meio do extrativismo - visa promover um desenvolvimento menos degradante e que proporcione crescimento econômico e geração de renda para a população local. Isso reflete a situação contraditória que se vive na região amazônica.

Ressalta-se a importância do reconhecimento das diversidades sociais e da relação entre atores diversos para se repensar o desenvolvimento. No entanto, além de reconhecer, é preciso interação entre os atores nas mais diversas escalas (local, regional, nacional) para que as possibilidades de desenvolvimento da atividade extrativista sejam pensadas sob diversas óticas e coerentes com as distintas realidades. Ações coletivas, parcerias colaborativas e cooperativismo apontam para uma

\section{Referências}

Acselrad, H. Políticas ambientais e construção democrática. In: Viana, G.; Silva, M.; Diniz, N. (Orgs.). O desafio da sustentabilidade: um debate socioambiental no Brasil. São Paulo: Editora Fundação Perseu Abramo, 2001.

Acselrad, H. As práticas espaciais e o campo dos conflitos ambientais. In: Acselrad, H. (Org.). Conflitos ambientais no Brasil. Rio de Janeiro: Relume Dumará, 2004. 294 p.

Almeida, A. W. B. de. Biologismo, Geografismo e dualismo: notas para uma leitura crítica de esquemas interpretativos da Amazônia que dominam a vida intelectual. In: Porro, R. (Ed.). Alternativa agroflorestal na Amazônia em transformação. Brasília, DF: EMBRAPA, Informação Tecnológica, 2009.

Araújo, E.; Barreto, P.; Martins, H. Áreas Protegidas críticas na Amazônia no período de 2012 a 2014. Belém: Imazon, 2015.

Aubertin, C. A ocupação da Amazônia: das drogas do Sertão à biodiversidade. In: Emperaire, L. (Ed.). A floresta em jogo: o extrativismo na Amazônia central. São Paulo: Editora Unesp, 2000. p. 23-30. possibilidade futura nessas relações, mas ainda é imperativo que haja diálogo e convergência entre os objetivos da maioria envolvida nestas arenas.

Dessa forma, extrativismo, desenvolvimento e sustentabilidade são temas cuja discussão está longe de ser esgotada. Por isso, é preciso investimento em pesquisa sobre a diversidade dos ecossistemas e categorias sociais que formam a Amazônia e sobre a maneira como tem se dado a interação entre homem e natureza nesse território. Por fim, é imprescindível que sejam construídas e implementadas políticas públicas consistentes, que abordem a importância e a grandeza da biodiversidade amazônica, incluindo a participação das comunidades e povos tradicionais que ali se constituem como um ecossistema vivo, necessário para sua conservação e para os rumos de um desenvolvimento sustentável.

Becker, B. K. Geopolítica da Amazônia. Estudos Avançados, 19(53), 71-86, 2005. Disponível em: <http://www. scielo.br/pdf/ea/v19n53/24081.pdf>.

Brasil. Medida Provisória $n^{\circ}$ 2.186-16, de 2001. Dispõe sobre o acesso ao patrimônio genético, a proteção e o acesso ao conhecimento tradicional associado, a repartição de benefícios e o acesso à tecnologia e transferência de tecnologia para sua conservação e utilização, e dá outras providências. Disponível em: $<$ http://www.planalto.gov.br/ ccivil_03/mpv/2186-16.htm>.

Brasil. Decreto 4.340, de 22 de agosto de 2002. Regulamenta artigos da Lei $\mathrm{n}^{\circ} 9.985$, de 18 de julho de 2000, que dispõe sobre o Sistema Nacional de Unidades de Conservação da Natureza - SNUC, e dá outras providências. Brasília, DF: 22/08/2002. Disponível em: <http://www.planalto.gov.br/ ccivil_03/decreto/2002/d4340.htm>.

Brüseke, F. J. O problema do desenvolvimento sustentável. In: Cavalcanti, C. (Org.). Desenvolvimento e natureza: estudos para uma sociedade sustentável. São Paulo: Cortez; Recife: Fundação Joaquim Nabuco, 2003. p. 29-40. 
Castelar, A. O Brasil precisa de uma estratégia de desenvolvimento? In: Sicsú, J.; Castelar, A. Sociedade e economia. Brasília, IPEA, 2009. p. 99-109.

Castro, E. Políticas de Estado e atores sociais na Amazônia contemporânea. In: Bolle, W.; Castro, E.; Vejmelka, M. (Orgs.). Amazônia: região universal e teatro do mundo. São Paulo: Globo, 2010. p. 105-122.

Costa, F. de A. Lugar e significado da gestão pombalina na economia colonial do Grão-Pará. Revista Nova Economia, Belo Horizonte, 20, 167-206, jan.-abr. 2010. Disponível em: $<$ http://www.scielo.br/pdf/neco/v20n1/05.pdf $>$.

Costa, F. de A. Formação agropecuária da Amazônia: os desafios do desenvolvimento sustentável. v. 1.2. ed. Belém: NAEA, 2012.

Elias, G. A.; Santos, R. dos. Produtos florestais não madeireiros e valor potencial de exploração sustentável da Floresta Atlântica no Sul de Santa Catarina. Ciência Florestal, Santa Maria, 26(1), 249-262, 2016.

Emmi, M. F. A oligarquia do Tocantins e o domínio dos castanhais. 2. ed. Belém: UFPA/NAEA, 1999. 174 p.

Emperaire, L.; Lescure, J. P. Apresentação. In: Emperaire, L. A floresta em jogo: o extrativismo na Amazônia central. São Paulo: UNESP, 2000.

Espada, A. L. V.; Sobrinho, M. V. Manejo comunitário e governança ambiental para o desenvolvimento local: análise de uma experiência de uso sustentável de floresta na Amazônia. Administração Pública e Gestão Social, 7(4), 169-177, 2015.

Ferreira, R. N. Amazônia: realidade cheia de perspectivas. Belém, Monografia (Concurso interno SUDAM) - SUDAM, 1989.

Fonseca, A.; Souza Jr., C.; Veríssimo, A. Boletim do desmatamento da Amazônia Legal. Belém: Imazon, 2015.

Hébette, J. O cerco está se fechando. Rio de Janeiro: FASE, 1991.

Hébette, J. A ocupação humana recente da microrregião de Marabá. In: Hébette, J. (Org.). Cruzando a fronteira: 30 anos de estudo sobre o campesinato na Amazônia. v. IV. Belém, PA: EDUFPA, 2004. p. 63-71.

Homma, A. K. O. A (ir)racionalidade do extrativismo vegetal como paradigma de desenvolvimento agrícola para a Amazônia. In: Costa, J. M. M. da (Coord.). Amazônia: desenvolvimento ou retrocesso. Belém: CEJUP, 1992. p. 163-207.

Homma, A. K. O. Extrativismo vegetal na Amazônia: limites e oportunidades. EMBRAPA: Centro de Pesquisa Agroflorestal da Amazônia Oriental. Brasília, 1993. 202 p.

Homma, A. K. O. Extrativismo vegetal ou plantio: qual a opção para a Amazônia? Revista Estudos avançados, 26(74), 167-186, 2012.

IBGE - Instituto Brasileiro de Geografia e Estatística. Censo Agropecuário 2006. Disponível em: <http://www. ibge.gov.br/home/estatistica/economia/pevs/2006/default. shtm>. Acesso em: mar. 2011.

IBGE - Instituto Brasileiro de Geografia e Estatística. Banco de dados agregados. 2014. Disponível em: <http://www.sidra.ibge.gov.br/bda/tabela/protabl. asp $\mathrm{c}=289 \& \mathrm{z}=\mathrm{p} \& \mathrm{o}=30 \& \mathrm{i}=\mathrm{P}>$. Acesso em: maio 2016 .

Kupfer, E. E. Amazônia: do cacau à borracha, da borracha à alta tecnologia. In: Bolle, W.; Castro, E.; Vejmelka, M. (orgs.). Amazônia: região universal e teatro do mundo. São Paulo: Globo, 2010. p. 185-205.

Lira, S. R. B.; Silva, M. L. M.; Pinto, R. S. Desigualdade e heterogeneidade no desenvolvimento da Amazônia no século XXI. Revista Nova Economia, 19(1), 153-184, 2009.

Litle, P. E. Ambientalismo e Amazônia: encontro e desencontros. In: Sayago, D.; Tourrand, J. F.; Bursztyn, M. (Orgs.). Amazônia: cenas e cenários. Brasília, DF: UnB, 2004.

Mota, D. M. da et al. As senhoras da mangaba. In: Mota, D. M.; Silva Júnior, J. F. da; Schmitz, H.; Rodrigues, R. F. de A. (editores técnicos). A mangabeira, as catadoras o extrativismo. Belém, Pará: Embrapa Amazônia Oriental; Aracaju, Sergipe: Embrapa Tabuleiros Costeiros, 2011. p. 95-127.

Paes-de-Souza, M. et al. O Produto Florestal Não Madeirável (PFNM) Amazônico açaí nativo: proposição de uma organização social baseada na lógica de cadeia e rede para potencializar a exploração local. Revista de Administração e Negócios da Amazônia, 3(2), 44-57, 2011.

Pinto, A. et al. Índice de Preço de Produtos da Floresta. IMAZON: Boletim Semestral 02/2011. Disponível em: $<$ http://www.imazon.org.br/publicacoes/precos-de-produ- 
tos-da-floresta/indice-de-precos-de-produtos-da-floresta-segundo-semestre-de-2011>. Acesso em: ago. 2012.

Pires, L.; Alves, F. B. Análise e síntese das lições e aprendizagem comunitária na produção de castanha-do-brasil (Bertholletia excelsa) e produção de instrumentos de difusão das boas práticas de manejo da espécie. Relatório de Consultoria. 2009. Disponível em: <http://portal.mda.gov. br/o/4050940>. Acesso em: jun. 2016.

Porro, N.; Shiraishi Neto, J. Conhecimento tradicional associado à biodiversidade em recursos de uso comum: a roça e a quebra de coco babaçu em quilombo na Amazônia Oriental. In: Guerra, G. A. D.; Waquil, P. D. (Orgs.). Desenvolvimento rural sustentável no Norte e no Sul do país. Belém: Paka-Tatu, 2013. p. 273-312.

Porto-Gonçalves, C. W. Amazônia, Amazônias. São Paulo: Contexto. 2001.

Redclift, M. Feitos a nossa imagem: o meio ambiente e a sociedade como discurso global. In: Arizpe, L. (Org.). As dimensões culturais da transformação global: uma abordagem antropológica. Brasília: UNESCO, 2001.

Redclift, M. Pós-sustentabilidade e os novos discursos de sustentabilidade. Revista Raizes, 21(1), 124-136, 2002.
Rego, J. F. Amazônia: do extrativismo ao neoextrativismo. Ciência Hoje, 25, 147, 62-65, 1999.

Sachs, I. Repensando o crescimento econômico e o progresso social: o papel da política. In: Abramovay, R. et al. (Orgs.). Razões e ficções do desenvolvimento. São Paulo: Editora Unesp/Edusp, 2001.

Soares, T. S. et al. Produtos florestais não madeireiros. Revista Científica Eletrônica de Engenharia Florestal, 11, 2008.

Velho, O. G. Capitalismo autoritário e campesinato. 2. ed. São Paulo: Difel, 1979.

Velho, O. G. Frentes de expansão e estrutura agrária: estudo do processo de penetração numa área da Transamazônica. 2. ed. Rio de Janeiro: J. Zahar, 1981.

Witkoski, A. C. Floresta de trabalho. In: Witkoski, A. C. Terras, florestas e água de trabalho: os camponeses amazônicos e as formas de uso dos recursos naturais. Manaus: Editora da Universidade Federal do Amazonas - EDUA, 2007. p. 250-288.

Zanirato, S. H.; Ribeiro, W. C. Conhecimento tradicional e propriedade intelectual nas organizações multilaterais. Ambiente \& Sociedade, X(1), 39-55, 2007. 